

\section{REVISTA \\ TEORÍA Y PRÁCTICA \\ DE LA \\ ARQUEOLOGÍA HISTÓRICA LATINOAMERICANA}

ISSN: 2250-866X (impreso) | ISSN: 2591-2801 (en línea)

AÑO VIII, VOLUMEN 9, PRIMAVERA DE 2019

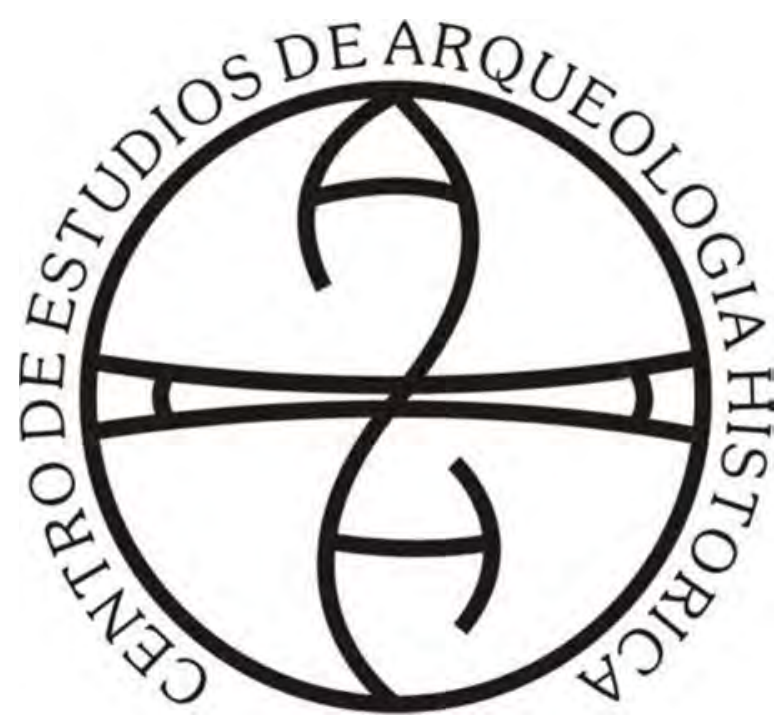

CENTRO de Estudios de ARqueOlOGía HistóricA

FACULTAD DE HUMANIDADES Y ARTES | UNIVERSIDAD NACIONAL DE ROSARIO 
(Universidad Nacional de Rosario, Universidad Nacional de Río Cuarto,

Universidad Nacional de San Juan, Universidad de la República, Universidad Nacional de Trujillo)

\author{
AUTORIDADES DE LA UNIVERSIDAD NACIONAL DE ROSARIO \\ RECTOR: Lic. Franco Bartolacci \\ VICE-RECTOR: Od. Darío Macía \\ SECRETARIO GENERAL: Prof. José Goity \\ SECRETARIA ACADÉMICO Y DE APRENDIZAJE: Dr. Marcelo Vedrovnik \\ SECRETARÍA DE CIENCIA TECNOLOGÍA E INNOVACIÓN \\ PARA EL DESARROLLO: Ing. Guillermo Montero.
}

\author{
AUTORIDADES DE LA FACULTAD DE HUMANIDADES Y ARTES \\ DECANO: Prof. Alejandro Vila \\ VICEDECANA: Prof. Marta Varela \\ SECRETARIA ACADÉMICA: Dra. Marcela Coria
}

\author{
AUTORIDADES DEL CENTRO DE ARQUEOLOGÍA HISTÓRICA \\ DIRECTORA: Dra. Ana Rocchietti \\ SECRETARIA: Prof. Nélida de Grandis \\ PROSECRETARIA: Lic. Marianela Bizcaldi
}

DIRECTORAS - EDITORAS:

Dra. Ana Rocchietti y Prof. Nélida De Grandis

SECRETARIA DE EDICIÓN: Dra. Irene Dosztal

Este número es co-edición de las ponencias

del VIII Congreso Nacional de Arqueología Histórica (2018) entre:

Centro de Estudios en Arqueología Histórica: Directora Ana Rocchietti

Centro de Estudios en Arqueología Regional: Director Fernando Oliva

Centro de Estudios en Arqueología Subacuática: Directora Mónica Valentini

Departamento de Arqueología, Escuela de Antropología: Director Fernando Oliva
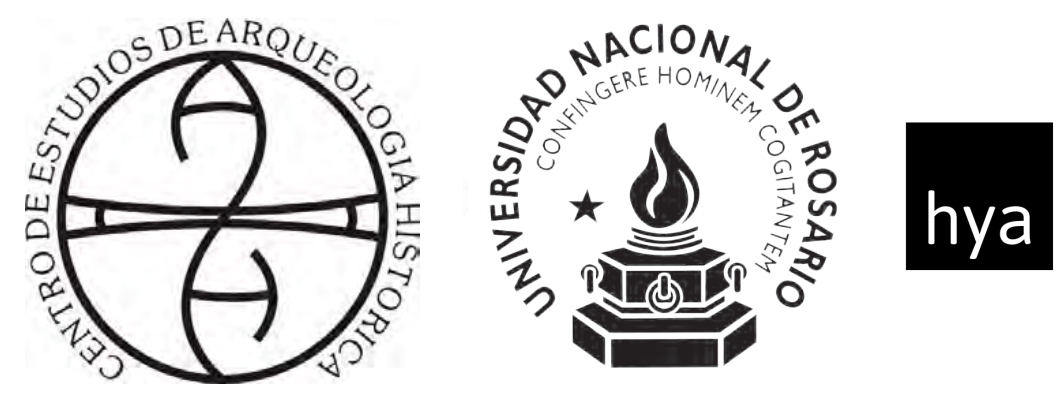

Facultad de Humanidades

y Artes_UNR
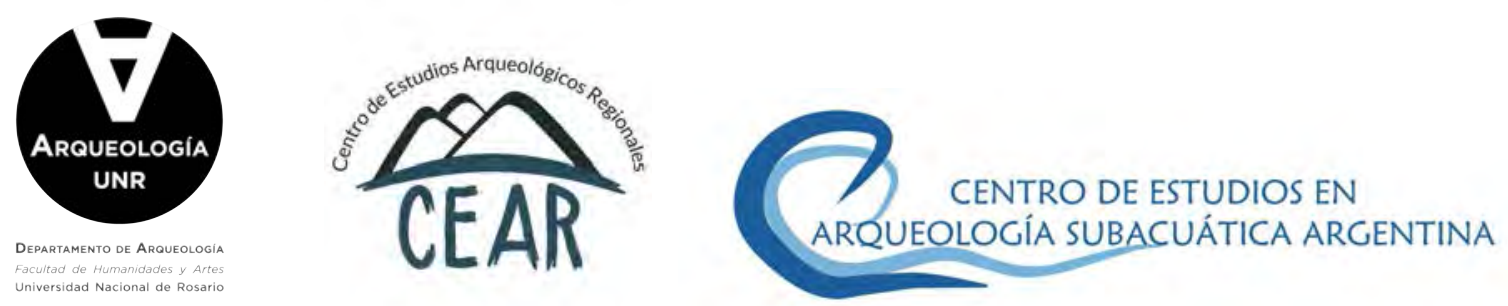
Comité Permanente de los Congresos Nacionales de Arqueología Histórica

Dr. Daniel Schávelzon (Universidad Nacional de

Buenos Aires)

Prof. María Teresa Carrara (Universidad Nacional de Rosario)

Prof. Carlos Baldassarre (Museo Municipal de Río

Grande, Tierra del Fuego) in memoriam

Dr. Mariano Ramos (Universidad Nacional de Luján, CONICET)

Dr. Horacio Chiavazza (Universidad Nacional de Cuyo)

Dra. Ana María Rocchietti (Universidad Nacional de

Rosario, Universidad Nacional de Río Cuarto)

Lic. Facundo Gómez Romero (Universidad Autónoma

de Barcelona)

\section{Comité Científico}

Dra. Tânia Andrade Lima (Universidade Federal do Rio de Janeiro)

Prof. Réginald Auger (CELAT/Département des

Sciences Historiques, Université Laval, Canadá)

Dr. Roberto Bárcena (Universidad Nacional de Cuyo, CONICET)

Dra. Marta Bonaudo (Universidad Nacional de Rosario, CONICET)

Dr. Leonel Cabrera (Universidad de la República, Uruguay)

Dr. Luis María Calvo (Universidad Católica de Santa

$\mathrm{Fe})$

Prof. Juan Castañeda Murga (Universidad Nacional de

Trujillo, Perú)

Dr. Carlos Ceruti (Museo de Ciencias Naturales y

Antropología "Prof. Antonio Serrano”. Paraná)

Dr. Horacio Chiavazza (Universidad Nacional de Cuyo)

Dra. Silvia Cornero (Universidad Nacional de Rosario)

Prof. Pedro Paulo Funari (Universidade Estadual de

Campinas, Brasil)

Lic. Jorge A. Gamboa Velásquez (Universidad Nacional

Santiago Antuñez de Mayolo, Perú)

Dr. Eduardo Alejandro García (Universidad Nacional de

San Juan, CONICET)

Prof. Nélida De Grandis (Universidad Nacional de

Rosario)

Dr. Juan Bautista Leoni (Universidad Nacional de

Rosario, CONICET)

Dra. Amancay Martínez (Universidad Nacional de San

Luis)

Dra. Catalina Teresa Michieli (Universidad Nacional de

San Juan, CONICET)

Lic. Fernando Oliva (Universidad Nacional de Rosario)
Ing. Adrián Pifferetti (Universidad Tecnológica Nacional Regional Rosario)

Dr. Mariano Ramos (Universidad Nacional de Luján, CONICET)

Dra. Ana María Rocchietti (Universidad Nacional de Rosario)

Dr. Daniel Schávelzon, (Universidad Nacional de Buenos Aires, CONICET)

Dra. Carlota Sempé (Universidad Nacional de La Plata)

Dr. Mario Silveira (Universidad Nacional de Buenos

Aires)

Dra. Silvia Simonassi (Universidad Nacional de Rosario)

Dra. Alicia Tapia (Universidad Nacional de Buenos Aires, Universidad Nacional de Luján)

Lic. Mónica P. Valentini (Universidad Nacional de Rosario)

Agrim. Benito Vicioso (Universidad Nacional de Rosario)

\section{Evaluaron este volumen}

Roberto Bárcena, María Teresa Boschin, Leonel Cabrera, Ulises Camino, María Rosa Carbonari, Carlos Ceruti, Horacio Chiavazza, Nicolás Ciarlo, Silvia Cornero, Eduardo Crivelli, Javier García Cano, Martín Gentinetta, María Laura Gili, Carlos Landa, Matilde Lanza, Melina Malandrino, Sebastián Pastor, Victoria Pedrotta, Josefina Piana, Mercedes Podestá, Mariano Ramos, Daniel Schavelzon, Diana Tamburini, Mónica Therrien, Mónica Valentini y María Teresa Boschin

\section{Diseño y diagramación}

Eugenia Reboiro

(eugenia.reboiro@gmail.com)

\section{Curadoría}

Ana Rocchietti e Irene Dosztal

Foto de tapa: Material arqueológico, del texto de Tapia et al.

\section{Propietario responsable:}

Facultad de Humanidades y Artes, Universidad Nacional de Rosario Centro de Estudios de Arqueología Histórica

Entre Ríos 758. Rosario, provincia de Santa

Fe (2000). Argentina.

Telf.: +54 (0341) 4802670

E-mail: ceahunr@gmail.com

Decreto Ley 6422/57 de Publicaciones

Periódicas 


\section{Índice}

Editorial

El origen del patrimonio histórico y su conservación integral en la contemporaneidad.

Yanina Aguilar

Prospección de basurales históricos de la ciudad de Rosario.

Soccorso Volpe y Gustavo Fernetti

Desconstrucción de un paisaje urbano. El Montevideo del extramuros colonial, aportes de la arqueología a su identidad actual. Ana Gamas

La Calota de Ameghino: reconsiderando un viejo tema desde la arqueología histórica.

Daniel Schávelzon

Análisis zooarqueológico de los restos hallados en una estructura sanitaria vinculada a momentos tempranos del actual barrio de Belgrano .71 Mario Silveira, Horacio Padula, Ricardo Orsini y Eva Bernat

La medida del tiempo: el reloj solar jesuita de La Cruz, provincia de Corrientes.

Fernando Oliva y María Cecilia Panizza

Sitio La Quinta: arqueología rural de campos serranos.

Flavio Ribero

Si no hay tabaco que no se note. Prácticas fumatorias en el fortin La Perra (1883-1885), La Pampa.

Alicia Tapia, Virginia Pineau y Melisa Ayelén Auge

El uso del tabaco y las pipas de caolin (clay pipes) en la frontera sur y oeste de la provincia de Buenos Aires en el siglo XIX.. .127

María del Carmen Langiano y Julio Fabián Merlo 
Patrimonio natural, urbano y arquitectónico de la costa en Mar del Plata. Federico Negroni

Huellas urbanas.

Ezequiel Serrot

Paisaje y patrimonio. La industria taninera en el siglo XX.

Provincia de Santa Fe.

Cristina Pasquali, Paola Milicic y Lara Ferré

Los desafíos de las arqueologías históricas latinoamericanas.

Andrés Zarankin

Sellos entre escombrales. Las lozas en el registro urbano

del Área Fundacional de Mendoza (siglo XIX y principios del siglo XX)

Lorena Puebla y Horacio Chiavazza

Evolución edilicia de la Plaza de Mayo de la Ciudad

de Buenos Aires (1580-1853).

Nicolás Ferrino

Gestión patrimonial en el rescate arqueológico y futuro Museo de Sitio

en Moreno 550, Ciudad Autónoma de Buenos Aires, Argentina.

María Eva Bernat, Ricardo Orsini, Horacio Padula y Mario Silvera 


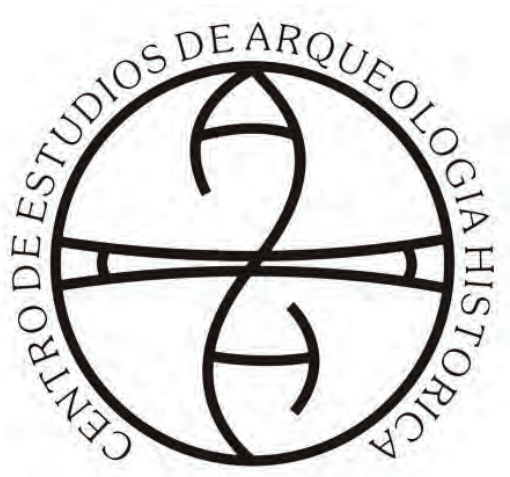

Centro de Estudios de Arqueología Histórica

Universidad Nacional de Rosario
Teoría y Práctica de la Arqueología Histórica

Latinoamericana | Año VIII. Vol. 9 | 2019

Revista del Centro de Estudios de Arqueología

Histórica, Facultad de Humanidades y Artes, Universidad Nacional de Rosario

https://teoriaypracticaah.unr.edu.ar/index.php/index ceahunr@gmail.com

ISSN en línea: 2591-2801

ISSN versión impresa: 2250-866X

\title{
Patrimonio natural, URbano y ARQuitectónico de la costa en Mar del Plata
}

\author{
Federico Negroni*
}

\section{Resumen}

La ciudad de Mar del Plata fue fundada en 1874 por Patricio Peralta Ramos en la costa bonaerense sobre el Océano Atlántico a unos 400 km al sur de la Ciudad de Buenos Aires. A lo largo de su historia ha pasado de ser un pequeño poblado dedicado a la explotación ganadera a convertirse en las primeras décadas del siglo XX en la ciudad balnearia elegida por la elite porteña para pasar los veranos junto al mar. Los avances sociales a partir de la década del 1940 transformarían a la ciudad en un gran polo turístico de las clases medias trabajadoras conformando la vibrante y cosmopolita ciudad costera de la actualidad.

Su paisaje natural representa un valor patrimonial particular en la costa atlántica por los accidentes geográficos de su costa conformada por pequeñas bahías, las salientes rocosas del macizo de Tandilia y la barranca desde su costa alta hacia el mar.

Este atípico paisaje de la línea costera ha sido modificado por la mano del hombre a lo largo de más de un siglo fundamentalmente en tres áreas: 1 . Las construcciones sobre el mar de escolleras y muelles destinados a preservar sus playas de la erosión marina.2. Las edificaciones que albergan distintos servicios para satisfacer las necesidades de los veraneantes sobre el nivel de la playa y las intervenciones paisajistas sobre la barranca natural. 3. La constitución del borde urbano sobre la costa mediante variados ejemplos arquitectónicos de distintos períodos.

Todos estos aspectos constituyen un valor patrimonial fundamental en la conformación de su identidad de ciudad costera.

Palabras clave: patrimonio, paisaje, costa, urbanismo, arquitectura

* Cátedra Pernaut de Historia de la Arquitectura de la Facultad de Arquitectura, Diseño y Urbanismo de la Universidad de Buenos Aires. Archivo de Imágenes Digitales de la Facultad de Arquitectura, Diseño y Urbanismo de la Universidad de Buenos Aires. Email: fedenegroni@gmail.com 
Teoría y Práctica de la Arqueología Histórica Latinoamericana | Año VIII. Vol. 9 | 2019

ISSN en línea: 2591-2801 | ISSN versión impresa: 2250-866X

\begin{abstract}
The city of Mar del Plata was founded in 1874 by Patricio Peralta Ramos on the coast of Buenos Aires over the Atlantic Ocean about $400 \mathrm{~km}$ south of the City of Buenos Aires. Throughout its history it has gone from being a small town dedicated to the cattle farming to become in the first decades of the 20th century in the seaside resort chosen by the Buenos Aires elite to spend summers. The social advances from the 1940s would transform the city in a great tourist pole for the working middle classes which helped to shape the vibrant and cosmopolitan coastal city of the present time.

Its natural landscape represents a particular patrimonial value on the Atlantic coast due to the geographical features of its coast formed by small bays, the rocky capes of the Tandilia massif and the landscape of its high coast facing the sea.

This atypical landscape of the coastline has been modified by the human hand throughout more than a century in three specific areas: 1 . The constructions on the sea of rockbreakwaters and piers destined to preserve its beaches from the marine erosion.2. The buildings that house different services to satisfy the needs of the tourists on the beach level and the landscaping interventions on the natural cliffs. 3. - The constitution of the urban border on the coast with varied architectural examples from different periods.

All these aspects constitute a fundamental patrimonial value in the conformation of its costal city identity.
\end{abstract}

Keywords: Heritage, landscape, coast, urbanism, architecture. Natural, urban and architectural heritage of the coast in Mar del Plata

\title{
Geografía y paisaje
}

La provincia de Buenos Aires se ubica en el centro este de la República Argentina sobre el Océano Atlántico. Geográficamente su paisaje se encuentra mayormente dominado por la Llanura Pampeana una vasta extensión de tierras completamente planas con escasa elevación sobre el nivel del mar y con suelos muy fértiles que en su estado natural se encontraban mayormente cubiertos por pastizales y algunas especies de árboles y arbustos que se ubicaban en las márgenes de arroyos y ríos que atraviesan este territorio en busca de descargar sus aguas en el mar. Se trata de terrenos sedimentarios formados en el cuaternario por la acumulación de limos provenientes de ambientes lacustres, fluviales o ingresos marinos en la zona costera.

Pero dentro de la región existen también dos accidentes geográficos atípicos tanto es su formación como en su data geológica. Se trata de los Macizos de Ventania al sur oeste del territorio bonaerense y el de Tandilia que se desarrolla desde el centro de la provincia en las cercanías de la ciudad de Olavarría hacia el sur este llegando a la costa sobre el Océano Atlántico en la Ciudad de Mar del Plata. El sistema de Tandiliaque tiene un recorrido de aproximadamente $340 \mathrm{~km}$ de largo por $55 \mathrm{~km}$ de ancho se formó hace unos 50 millones de años por una falla en el basamento de granito que arrastró sucesivas formaciones sedimentarias como las de dolomitas y calcitas de la zona de Olavarría de hace 300 millones de años o los de cuarcita blanquecina en la zona de Sierra de los Padres y Mar del Plata de hace 100 millones de años. Sus mayores elevaciones se dan en las proximidades de la ciudad de Tandil donde el basamento granítico se eleva a unos 500 metros sobre el nivel del mar. La presencia de estas formaciones interrumpe el paisaje llano y monótono de la región pampeana para dar lugar a praderas más altas intercaladas con sierras de pendiente suave con afloramientos rocosos. 
Este paisaje en el interior del territorio también tiene su efecto en la costa. La mayor parte de la Provincia de Buenos Aires donde predomina la llanura pampeana tiene un paisaje costero caracterizado por extensas playas rectas, arenosas y de mar abierto que se prolongan ininterrumpidas a lo largo de cientos de kilómetros. El límite entre la playa y la llanura está dado por la formación de médanos de arena que comenzaron a formarse hace un millón y medio de años y continúan en constante proceso de transformación y regeneración por el accionar de los vientos atlánticos.

Al igual que la llanura es interrumpida por las sierras estas costas infinitas son interrumpidas en la zona de Mar del Plata por los últimos afloramientos rocosos del Macizo de Tandilia que se hunde en el Océano Atlántico en el Cabo Corrientes ubicado en pleno casco urbano de la ciudad a escasos tres kilómetros hacia el sur de su área fundacional. El paisaje de la costa de Mar del Plata se caracteriza por una sucesión de pequeñas bahías que se desarrollan entre distintas salientes, puntas y cabos rocosos. A diferencia del resto de la costa baja bonaerense típica de llanura aquí se da un paisaje completamente distinto, recortado y de costa alta con barrancas hacia las playas de arena o acantilados de roca hacia el océano.

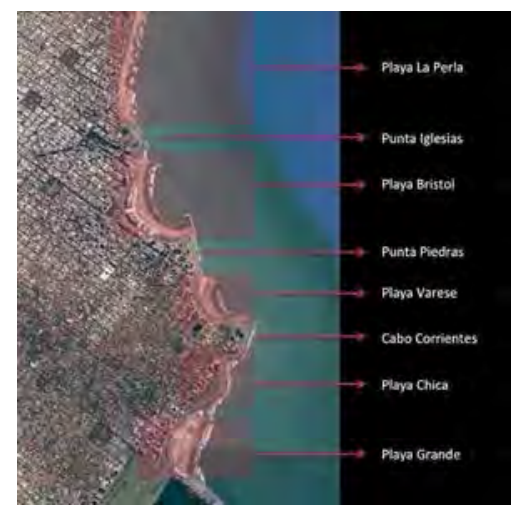

Figura 1: Imagen satelital de la costa en Mar del Plata (fuente Google Earth).

\section{Historia de Mar del Plata:}

Los primeros pobladores de esta zona fueron tribus nómades de indios Pampas que dominaron la región previamente a la llegada de los españoles y la colonización. Hacia mediados del Siglo XVIII religiosos jesuitas crearon algunas reducciones en la zona cercana a la Laguna y Sierra de Los Padres ubicadas a aproximadamente 12 kilómetros de la costa atlántica hacia el interior del territorio bonaerense. Justamente de la presencia en la zona de estas reducciones y los padres jesuitas es que toman su nombre actual. Los jesuitas fueron expulsados de todos los territorios pertenecientes a la corona española en América en 1767 y a partir de ese año estas tierras quedaron vacantes y abandonadas. En 1819 luego de la independencia Argentina estas tierras son asignadas para la explotación ganadera a Pedro de Alcántara Capdevila. El establecimiento conocido con el nombre de Estancia Laguna de los Padres fue pasando por distintos propietarios hasta que en el año 1856 la compra una sociedad brasileña comandada por José Coelho de Meyrelles quien decide instalar un saladero para tratar las carnes y un muelle para poder luego trasportarlas por barco hacia Buenos Aires. El saladero y el muelle fueron completándose con otras estructuras edilicias de servicios para esta empresa dedicada a la ganadería y el procesamiento de carnes y constituyeron las primeras construcciones de lo que hoy es la ciudad de Mar del Plata. Pero esta sociedad brasileña no tuvo éxito y en el año 1860 Patricio Peralta Ramos adquiere las tierras con 
Teoría y Práctica de la Arqueología Histórica Latinoamericana | Año VIII. Vol. 9 | 2019

ISSN en línea: 2591-2801 | ISSN versión impresa: 2250-866X

toda su infraestructura incluyendo el saladero y el muelle. El nuevo propietario se dispuso a continuar el desarrollo del establecimiento añadiendo nuevas construcciones y conformando un pequeño caserío dedicado a la explotación ganadera. La principal construcción de este período es sin dudas la Capilla de Santa Cecilia que Peralta Ramos edifica en el año 1873 en honor a su fallecida esposa Cecilia Robles. En ese mismo año solicita al gobierno provincial una licencia para la traza y fundación formal de un pueblo. La traza en forma de cuadrícula comenzaría a construirse al año siguiente a partir de la edificación más importante existente en la zona, la capilla de Santa Cecilia que es actualmente el edificio más antiguo de la ciudad. En el año 1877 llega a radicarse en la zona y hacerse cargo de la concesión del saladero Pedro Luro un hombre de espíritu emprendedor que sería en gran parte responsable de cambiar el destino de este insipiente poblado rural. Luro comenzó comprando varios terrenos cercanos al mar consciente del potencial que significaba esa costa única sobre el Océano Atlántico. El ferrocarril proveniente de Buenos Aires llegaría a la ciudad en 1886 y con él las múltiples posibilidades de desarrollo urbano. El 8 de enero de 1888 una sociedad anónima presidida por Pedro Luro inaugura el Bristol Hotel frente a la entonces denominada Playa Sur que se transformaría en las décadas siguientes en el polo de atracción turístico más importante de las clases adineradas porteñas. Para estos años el pequeño poblado dedicado a la explotación ganadera creado por Peralta Ramos se había transformado con la intervención de Luro en el principal centro turístico y balneario del país.

Las primeras décadas del Siglo XX fueron el escenario de un gran desarrollo urbano, La ciudad vio en estos años la construcción de importantes obras urbanísticas, como el Paseo General Paz sobre la costa de la Playa Bristol diseñado por el paisajista Carlos Thays en 1913, hasta las sucesivas ramblas primero de madera y luego de mampostería y estructura de hierro que brindaban innumerables servicios a los veraneantes en la playa. Pero también se dio la construcción de gran número de villas y residencias particulares de las familias pertenecientes a la elite de Bueno Aires que ya tomaban la costumbre de pasar los veranos frente al mar en verdaderos palacetes construidos en este particular enclave en la costa atlántica. Su arquitectura se caracterizó por el estilo ecléctico de sus construcciones inspiradas en diversos géneros del pasado como el Belvedere construido en 1908 por Carlos Nordmann sobre la saliente rocosa de Punta Piedras en el extremo sur de Playa Bristol. La construcción inspirada en un castillo medieval fue diseñada con el propósito de contemplar el esplendor del paisaje de la costa y el mar. Esta estructura aún subsiste y es conocido como el Torreón del Monje y aunque fue ampliado y modificado en varias oportunidades aún es posible reconocer el edificio original. Esta transición de pequeño poblado dedicado a la explotación ganadera a ciudad balnearia se refuerza en 1909 cuando se da inicio a la construcción del puerto de ultramar al sur de la ciudad que hasta entonces utilizaba la Bahía Bristol y el muelle de Meyrelles y sus sucesivas reconstrucciones como puerto natural. El estallido de la Primera Guerra Mundial en Europa consolidaría aún más su destino turístico cuando las familias adineradas se ven imposibilitadas por la guerra de pasar largas temporadas en el viejo continente. La inspiración europea de sus costumbres y de su arquitectura le valió a la ciudad de Mar del Plata por aquellos primeros años del Siglo XX el apodo de "La Biarritz Argentina” en alusión a la ciudad balnearia vasco-francesa. Fueron esas primeras décadas donde reinó el estilo pintoresquista en sus construcciones.

Otro gran cambio en el destino de la ciudad se da a partir del año 1938 y se extiende a casi toda la década de 1940. Durante este período se realizan una serie de proyectos de obras públicas como la pavimentación de la ruta nacional N² que une Buenos Aires con Mar del Plata, la construcción del nuevo Palacio Municipal y la de la Nueva Rambla Bristol con el Hotel Provincial y el casino todos éstos proyectados por el Arq. Alejandro Bustillo.La imponente imagen de su arquitectura de tardía inspiración clásico-francesa le darían su impronta definitiva a este sector de la costa de la ciudad. Al mismo tiempo 
se consolidarían nuevos sectores hacia las playas del sur con la construcción de balnearios de estilo racionalista con una cierta inspiración en la arquitectura naval en la zona de Playa Grande. Mar del Plata que había pasado a ser la ciudad balnearia de la elite comenzaba su etapa de democratización que se consolidaría en los años siguientes con los avances sociales impulsados durante los dos primeros mandatos presidenciales de Juan Domingo Perón. A Mar del Plata comenzaron a llegar verano tras verano las clases medias y trabajadoras y se transformó hacia la mitad del Siglo XX en un verdadero ícono del turismo argentino y en un sinónimo de vacacionar en el imaginario popular.

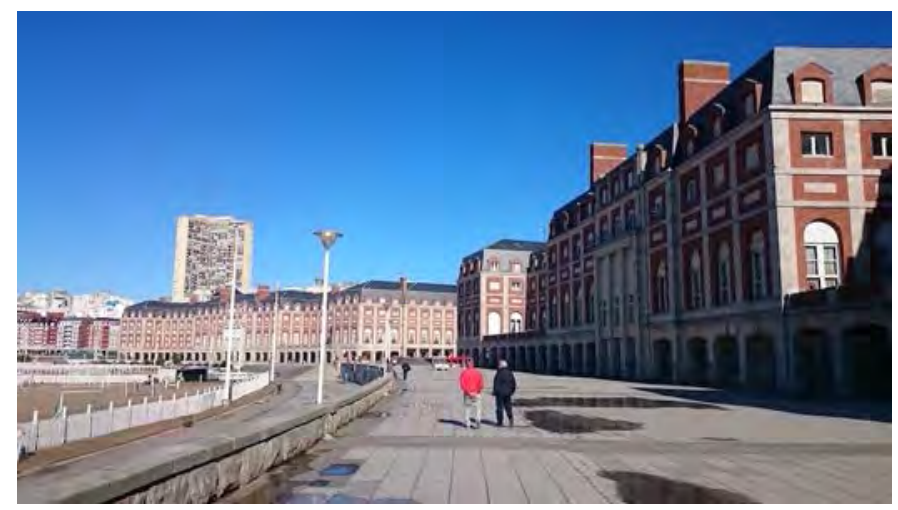

Figura 2: Rambla Playa Bristol con el Casino y el Hotel Provincial, Arq. Alejandro Bustillo.

\section{Mar del Plata en la actualidad:}

Actualmente la ciudad sigue siendo un gran atractivo turístico en especial durante las temporadas de verano pero en cierta forma también lo es durante todo el año. Del mismo modo a superado ese destino puramente recreacional para transformarse en una vibrante ciudad costera con vida propia y una población permanente que supera los 600.000 habitantes. Cada verano recibe cerca de 2.000.000 de turistas. Posee una gran vida cultural y oferta de espectáculos en sus diversos teatros, museos y centros culturales como así también varias universidades públicas y privadas, servicios de salud de primer nivel y una incomparable oferta gastronómica. Su infraestructura de servicios está pensada y dimensionada para abastecer las necesidades de los millones de turistas del verano lo cual resulta en una ciudad muy completa para sus habitantes el resto del año. A lo largo de su desarrollo durante todo el Siglo XX vio modificar vertiginosamente su paisaje natural y sus construcciones al ritmo de las cambiantes necesidades de la sociedad. Sin embargo su costa aún hoy y a pesar de las múltiples intervenciones sufridas en todos estos años constituye un conjunto de valor patrimonial que justamente refleja tanto su naturaleza pura como su desarrollo histórico.

La costa marplatense es escenario de un conjunto natural y urbano arquitectónico que fue intervenido en reiteradas ocasiones por la mano del hombre fundamentalmente en tres áreas:

- Las construcciones sobre el mar de escolleras y muelles destinados a preservar sus playas de la erosión marina.

- Las edificaciones que albergan distintos servicios para satisfacer las necesidades de los veraneantes sobre el nivel de la playa y las intervenciones paisajistas sobre la barranca natural.

- La constitución del borde urbano sobre la costa mediante variados ejemplos arquitectónicos de distintos períodos. 
Teoría y Práctica de la Arqueología Histórica Latinoamericana | Año VIII. Vol. 9 | 2019

ISSN en línea: 2591-2801 | ISSN versión impresa: 2250-866X

Las intervenciones en estas tres áreas tienen sus características particulares en cada uno de los distintos sectores del frente costero de la ciudad. Es notable como cada uno de ellos posee una identidad propia y al mismo tiempo todo el frente costero se puede apreciar la unidad del paisaje tanto urbano como natural. Analizaremos los sectores correspondientes al casco urbano desde Playa La Perla al Norte hasta el Puerto en el sur.

\section{Muelles y escolleras:}

Si hay algo que se mantiene como un común denominador en casi todas lasplayas céntricas de la ciudad es la presencia de muelles y escolleras de piedra que como hemos visto es un recurso que abunda en la región. Su razón de ser está ligada con las corrientes marinas y la propia constitución geográfica de esta costa alta y rocosa como también del propio desarrollo urbano de la ciudad que agravó el problema natural de erosión marina que tuvieron desde siempre estas playas atlánticas. La ciudad creció mucho y en forma rápida y con ese cambio cada vez fueron más escasos los terrenos con capacidad de absorción de las aguas que caen con frecuencia sobre el territorio como consecuencia de las fuertes tormentas atlánticas. Inevitablemente toda el agua que cae sobre el casco urbano va a parar a sus playas y al mar lo cual acelera el proceso de pérdida de arena. En una ciudad que creció exponencialmente como balneario y que se popularizó como uno de los destinos turísticos preferidos por los argentinos la disminución de la superficie de arena en sus playas que en algunos casos llegó a la desaparición total de las mismas es un problema relevante y que de diferentes maneras el municipio tuvo que atender. La mayor parte de las intervenciones se dieron durante la década de 1980 cuando gran parte de la superficie de arena de las playas céntricas se había perdido o estaba en franco retroceso.

Estas acciones tienen en común que se trató de preservar y fomentar la acumulación de arena en las playas mediante la construcción de escolleras de piedra. Aunque la forma de estas construcciones sobre el mar va a variar de sector en sector dependiendo de las necesidades particulares de cada uno y de las tendencias que fueron cambiando a lo largo de los años en cuanto a la preservación del entorno natural y el ecosistema de la costa atlántica.

Analizaremos las intervenciones a lo largo de un recorrido por la costa de norte a sur. En Playa La Perla por ejemplo se optaron por escolleras en forma de “ $T$ ” ubicadas sobre el mar en forma perpendicular a la línea de playa. Esta playa al norte del centro de la ciudad es una de las más rectas y abiertas hacia el mar y donde la arena había disminuido considerablemente. La sucesión de escolleras con esa forma tan particular también llamada “trampa de arena” generó que en poco tiempo volviera a acumularse arena sobre su playa que pasó de ser recta a estar conformada por un conjunto de pequeñas bahías que se desarrollan entre las escolleras, esto constituye en principal efecto positivo de esta intervención sobre la costa, pero también trajo ciertos aspectos negativos.El principal es que las aguas de estas bahías suelen estancarse y acumular desechos como ramas y hojas secas luego de las tormentas. Esta situación interrumpe el proceso natural de auto-limpieza del mar y altera al mismo tiempo el ecosistema marino.

Siguiendo hacia sur y luego de pasar Punta Iglesias se llega a la Playa Bristol, una pintoresca bahía natural con forma de medialuna. Esta fue la playa donde surgió Mar del Plata y la que se usó inicialmente como puerto natural por sus aguas calmas. La erosión marina en esta bahía no tiene los mismos efectos que en otras playas por lo que no fue necesario la construcción de escolleras para retener la arena, en su lugar hay una serie de muelles de hormigón armado perpendiculares a la costa que se adentran en las aguas de la bahía. Uno en particular es una pieza fundamental del patrimonio costero de la ciudad. El muelle del Club de Pesca se inauguró en 1927 en el mismo enclave sobre la playa donde estuvo el pri- 
mer muelle con estructura de madera de Meyrelles a finales del Siglo XIX cuando el destino de ciudad balnearia era impensado. La construcción consta un edificio de mampostería y estructura de hormigón armado que se alza sobre una plataforma sostenida por pilotes del mismo material clavados en la arena y se desarrolla hacia el mar en forma perpendicular a la costa. Más allá de su función específica el muelle a lo largo de los años se transformó en un verdadero ícono de la costa marplatense presente en infinidad de imágenes fotográficas que atestiguan el paso de muchas generaciones de veraneantes y es un símbolo de la playa más céntrica y popular de la ciudad. Solamente en cada uno de los extremos de esta bahía se construyeron recientemente escolleras de piedra en forma de rompeolas con el fin de completar su forma natural y favorecer la mayor acumulación de arena en la playa.

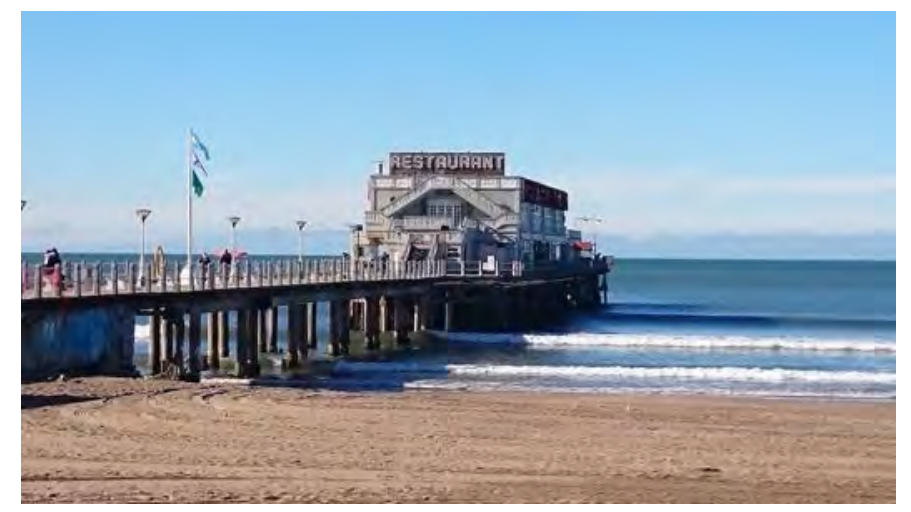

Figura 3: Muelle del Club de Pesca.

Al extremo sur de la Bahía Bristol encontramos la saliente rocosa de Punta Piedras y más allá una pequeña bahía que a lo largo de la historia ha tenido muchos nombres. Originalmente conocida como Playa de Saint James luego fue denominada como Playa de Los Ingleses hasta que durante el conflicto por las Islas Malvinas entre Inglaterra y Argentina en 1982 pasó a llamarse Playa Varese. Este fue uno de los sectores de la costa que fue más castigado por la erosión al punto tal que hacia la década de 1970 prácticamente no quedaba casi arena en la playa y las olas del mar pegaban frecuentemente contra en muro de piedra del paseo costero. Aquí la solución adoptada fue la de construir en ambos extremos de la bahía dos grandes escolleras de piedra que cerraron aún más su forma natural de herradura. En poco tiempo la arena comenzó a acumularse en ambos extremos próximo a las escolleras para luego completar una ancha franja de playa en todo su recorrido. Hoy en día es una de las más amplias y aprovechables de la ciudad por sus aguas calmas y protegidas ideales para la práctica de deportes acuáticos. Aunque también es cierto que algunos días dependiendo de las corrientes marinas y las tormentas sus aguas pueden acusar la presencia de deshechos y acumulación de algas. 


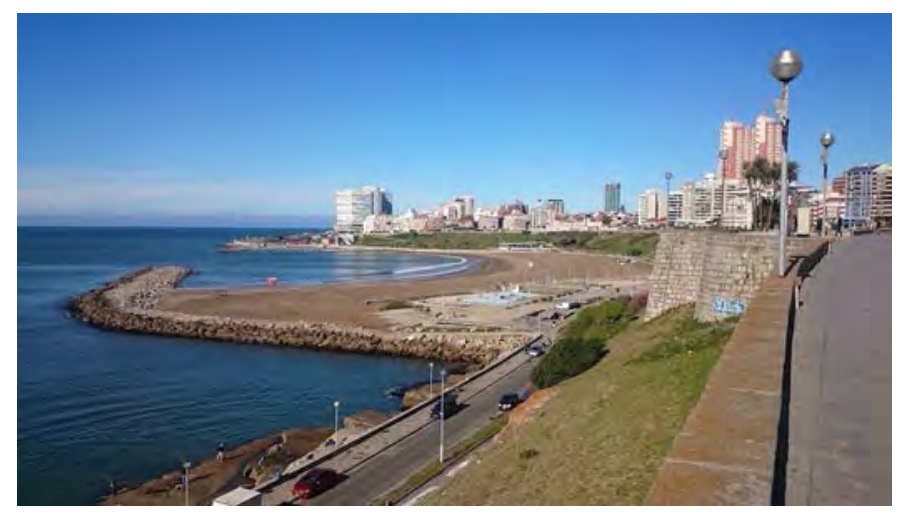

Figura 4: Playa Varese.

Al sur de esta bahía está el Cabo Corrientes con sus formaciones rocosas erosionadas por el mar y los vientos durante millones de años. Es allí mismo donde el macizo de Tandilia se adentra en las aguas del Océano Atlántico y forma el extremo más al este de la costa de la ciudad. Abrigada bajo el lado sur del cabo había una pequeña playa llamada Playa Chica que supo tener una estrecha franja de arena en las primeras décadas del Siglo XX. En este sector no se realizaron intervenciones sobre la costa y el mar y es por tal razón que hoy en día la poca arena que había ha desaparecido por completo sólo hay rocas que resisten estoicamente el embate de las fuertes olas del mar.

Al finalizar este sector de acantilados se encuentra la última de las playas céntricas de la ciudad. Playa Grande como su nombre lo indica posee una gran extensión de arena protegida de las corrientes marinas del sur por la enorme escollera norte del puerto de Mar del Plata. También en los años 2000 se construyó otra escollera de piedra de menor recorrido en el extremo norte de la playa con el fin de aumentar la acumulación de arena y facilitar la preservación de estructuras edilicias costeras que tenían sus cimientos erosionados por la acción del mar. Toda esta problemática de las playas céntricas de la ciudad se encuentra también ligada a la construcción del puerto de ultramar en los comienzos del Siglo XX. La deriva del mar como consecuencia de las corrientes marinas arrastra la arena del fondo del mar en dirección sur - norte. Cuando se construyó el puerto la escollera sur que se interna unos 2700 metros en el mar interrumpe este proceso que naturalmente renovaba la arena de las playas.

\section{Edificios destinados a brindar servicios de playa e intervenciones paisajísticas sobre la barranca natural:}

Las playas de Mar del Plata no sólo tienen mar y arena, existen desde que esta ciudad comenzó a recibir el turismo veraniego una infinidad de estructuras edilicias destinadas a brindar una enorme cantidad de servicios a los visitantes. Desde baños,vestuarios, restaurantes, piscinas, tiendas y hasta los tan controvertidos espacios privados de sombra en la arena (toldos y sombrillas) que reducen considerablemente el espacio público en las playas. Lo cierto es que más allá de esta polémica la presencia de balnearios que brindan servicios a los turistas es una cuestión cultural del veraneante en esta zona muy probablemente influenciado por el clima atlántico ventoso y fresco incluso durante el verano. Con toda esta batería de servicios disponible estas playas atlánticas se tornan más aprovechables aun cuando el clima no sea el más favorable. A lo largo de su historia se han construido en las playas de la ciudad distintos complejos balnearios que revisten un interés arquitectónico particular. En algunos casos fueron diseñados por arquitectos 
de renombre y en otros son fieles representantes de su época por su estilo arquitectónico. Evidentemente con el paso de las décadas estos edificios han pasado a formar parte del patrimonio arquitectónico de Mar del Plata y de su identidad de ciudad balnearia. En este sentido, hay tres en particular que revisten un gran valor arquitectónico patrimonial. Entre ellos y el borde urbano existe ese espacio que ocupan sobre la barranca natural distintos paseos y parques costeros que también presentan intervenciones paisajísticas.

En Playa La Perla en el año 1986 se inaugura un complejo de balnearios diseñado por el arquitecto Clorindo Testa, su propuesta busca re-editar la memoria de las antiguas ramblas de madera del 1900 con diferentes niveles que albergan servicios varios y planteaban al mismo tiempo una suerte de paseo lineal costero desde el cual se aprecia el paisaje natural y urbano. Los balnearios de Testa toman estas ideas y se materializan en hormigón armado y mampostería de ladrillos vistos dos materiales que resisten bien los embates del clima marítimo. Estos edificios también toman el desnivel entre el borde urbano y el nivel de playa organizando sus funciones en tres niveles. En el inferior están los baños y vestuarios, administración y depósitos. En el nivel intermedio hay tiendas, bares y restaurantes todos unidos por una pasarela en altura que permite el realizar un paseo de frente al mar al mismo tiempo que da acceso al complejo desde el lado de la ciudad. Porúltimo, los techos de estos edificios están unidos por una serie de escaleras y terrazas transitables que recomponen a modo de paseo lineal la unidad del conjunto. Desde esa altura se aprecia tanto el paisaje marino hacia un lado como la ciudad y su frente urbano del otro.

En Playa Varese se da una situación particular del paisaje, la costa a lo largo de esta bahía de unos mil metros de extensión presenta un nivel superior, el Boulevard Marítimo Patricio Peralta Ramos que constituye el borde de la ciudad frente al mar, por debajo se desarrolla la barranca natural del terreno hacia el Paseo Jesús Galindez que conforma la nivel inferior y adyacente a la playa. Este sector costero de la ciudad sufrió muchos cambios a lo largo del Siglo XX. Originalmente cuando era conocida como Playa de Saint James y luego como Playa de Los Ingleses la barranca esta ocupada por varios hoteles turísticos que perdieron interés al desaparecer la playa y entraron en deterioro y abandono generalizado. En la década de 1980 durante la última dictadura militar los pocos que quedaban fueron demolidos y se optó por dejar la barranca natural del paisaje sin estructuras edilicias. Luego de la recuperación de la playa pasaron varias décadas hasta que en 2005 el municipio decide lanzar una convocatoria para la intervención y puesta en valor de este sector desde Punta Piedras hasta el Cabo Corrientes. Durante los años subsiguientes se realizó el proyecto ideado por los Arquitectos José Solla y Eduardo Zak que plantea un abordaje integral de los tres niveles que comprenden la costa: la playa y sus servicios, el paseo inferior y el tratamiento paisajístico de la barranca hasta la parte alta y el borde urbano.

A nivel bajo la propuesta los edificios de servicios balnearios y estacionamientos subterráneos se desarrollan en una sola planta con el fin de alterar lo menos posible el paisaje natural de la playa, cabe aclarar que Playa Varese sólo posee balnearios privados en ambos extremos de la bahía dejando una gran extensión de playa pública. Estas dos construcciones además de una más pequeña en el centro de la bahía que alberga los baños públicos resuelven sus cubiertas de hormigón como una serie de plazas secas que plantean una expansión del paseo bajo y resuelven mediante rampas y escalinatas el acceso desde ese al nivel a la arena. Las operaciones sobre el paisaje natural de la barranca se dan con un abordaje muy similar. Mediante 4 rampas de hormigón armado y una escalinata que acompañan la pendiente se resuelve el acceso al nivel inferior desde lo alto en la mayor parte de su extensión la barranca fue tratada como un gran parque en pendiente que evidencia el terreno natural sin mayores intervenciones salvo tres edificios recostados sobre la barranca que albergan locales gastronómicos y que buscan mimetizarse con el paisaje mediante la incorporación de cubiertas verdes. Así es que el tratamiento homogéneo del conjunto logra establecer un diálogo con el paisaje natural sin dejar de proveer de servicios a los turistas. 


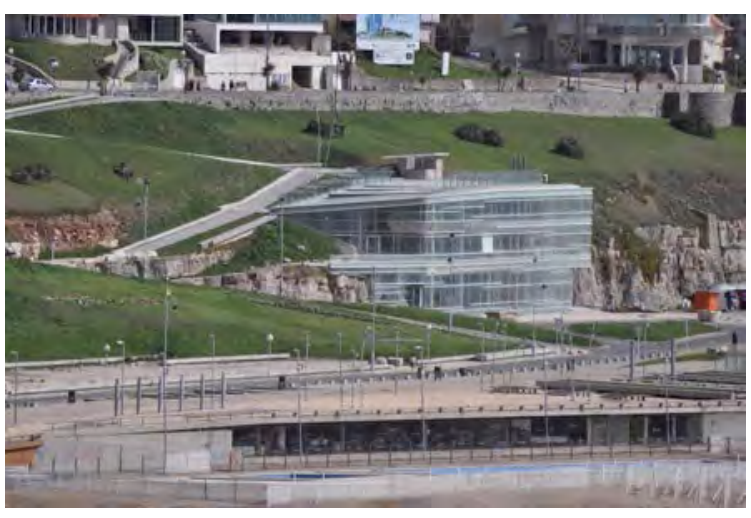

Figura 5: Balnearios Playa Varese.

El otro complejo balneario de importancia por su arquitectura es el que se construyó en Playa Grande durante el período de democratización de Mar del Plata hacia finales dela década de 1930.

Allí se construyeron una serie de edificios en estilo racionalista a nivel de la playa que albergan los servicios de los balnearios y locales gastronómicos. A lo largo de la extensión de la playa se desarrollan estos edificios muy simpes caracterizados por la pureza de sus volúmenes y detalles arquitectónicos como las ventanas circulares inspiradas en la ingeniería naval y sus muros revocados y pintados en color claro casi blanco y sin ornamento. En el centro se encuentra el acceso principal a la playa desde lo alto de la costa mediante escalinatas de piedra que acompañan la pendiente natural del territorio. En el nivel medio una gran terraza por sobre los edificios de los balnearios con una piscina con vista al mar completa la oferta de servicios a los turistas. Por debajo de esta terraza pasa la calle de accesos a los estacionamientos subterráneos construidos bajo la barranca.

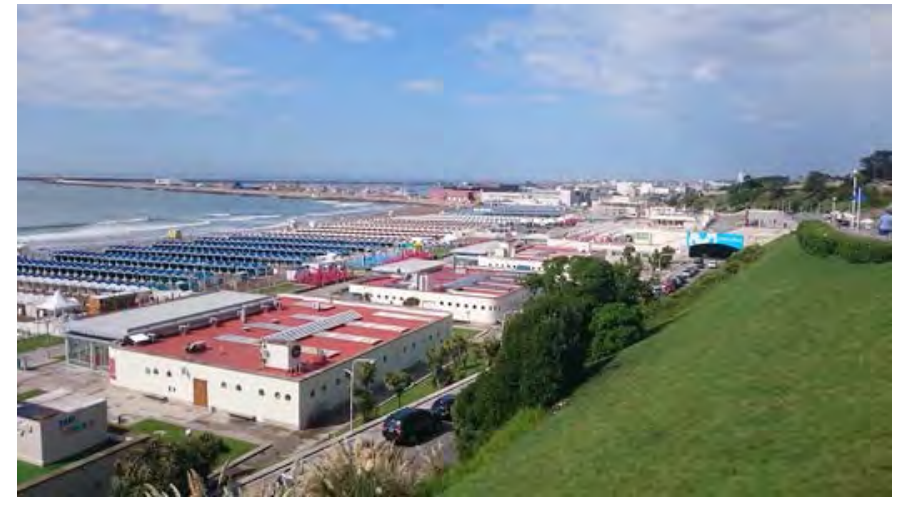

Figura 6: Balnearios Playa Grande.

Todo este conjunto muy homogéneo se remata en los dos extremos de la playa por dos edificios que guardan su relación en cuanto a estilo pero que al mismo tiempo adoptan formas diferenciadas. Hacia el extremo sur pegado al puerto se ubica la sede del Yacht Club Argentino con sus dos frentes bien diferenciados. La fachada que da a la ciudad de estilo Art Deco con basamento y torre central de piedra y composición simétrica contrasta con la fachada hacia el mar que evidencia un estilo más racionalista con grandes ventanas apaisadas e incluso la incorporación de una escalera en metal que une la planta 
baja y la terraza del primer piso a la manera de las escaleras que dan accesos a las distintas cubiertas en un barco.
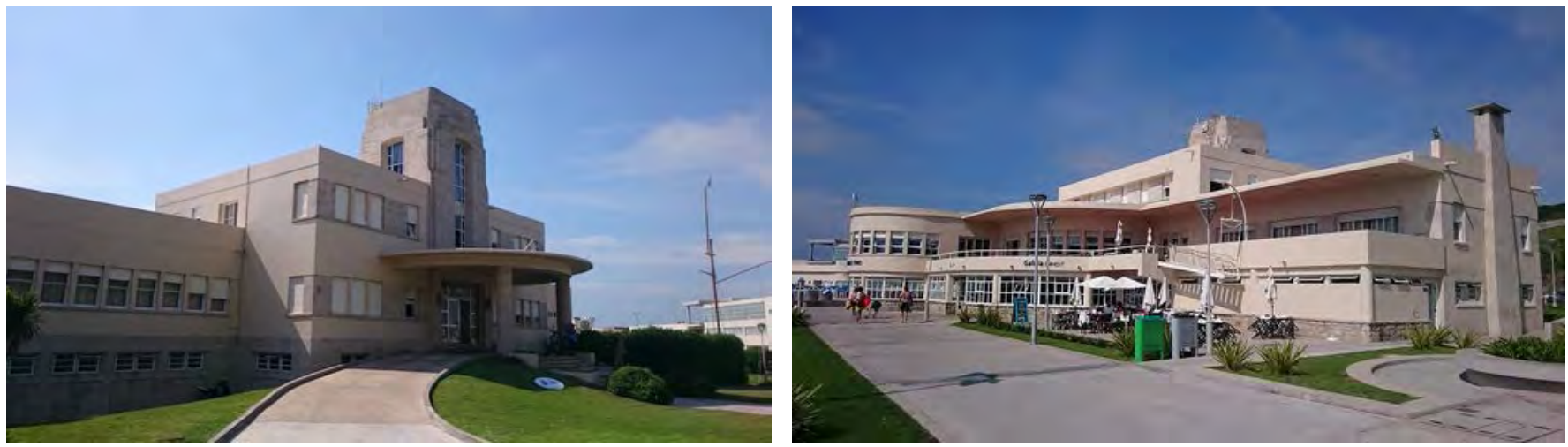

Figura 7 y 8: Yacht Club Argentino Playa Grande.

En el extremo norte se encuentra otro edificio racionalista de 1938 que en sus orígenes fue la Confitería "Normandie", se trata de un edificio de volúmenes puros que se eleva sobre una gran plataforma con terrazas perimetrales sustentada sobre pilotis de hormigón armado.

Durante el Siglo XX sufrió varios cambios de destino. Por ejemplo durante la década de 1970 albergó al Instituto de Biología Marina pero el retroceso de la playa comenzó a deteriorar tanto el edificio y sus cimientos que hacia el año 2000había quedado obsoleto y abandonado. Con la construcción bajo sus cimientos de una nueva escollera y la recuperación de la playa se pudo concretar en el año 2004 la propuesta de re-funcionalización y puesta en valor a cargo del estudio local de arquitectura Mariani - Pérez Maraviglia. Actualmente "La Normandina” es un complejo gastronómico, cultural y de entretenimiento nocturno que aprovecha la estructura original y sus privilegiadas vistas al mar, la costa y la ciudad.

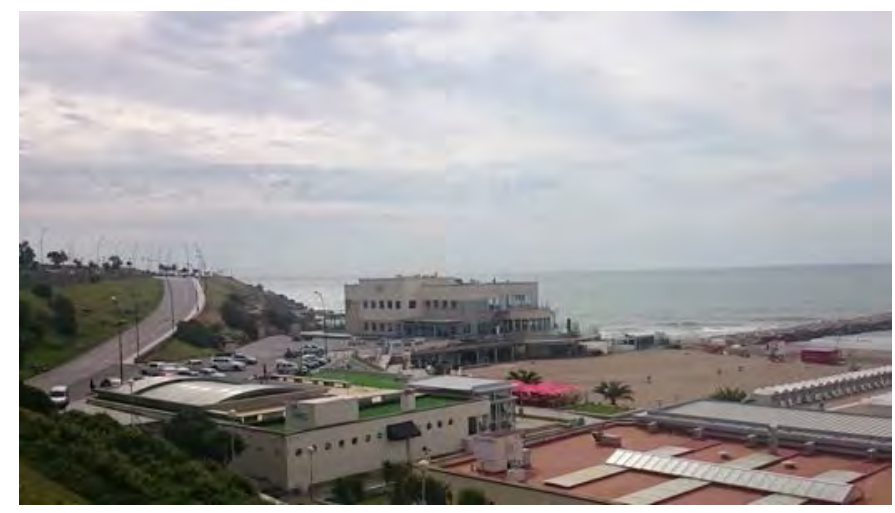

Figura 9: Complejo La Normandina en Playa Grande.

\section{El borde urbano frente al mar:}

A lo largo del tiempo la ciudad de Mar del Plata a pasado por infinitas situaciones de cambio tanto en su estructura urbana como en su pintoresca costa. La primera línea de edificios constituye ese borde don- 
de confluyen las fuerzas de lo urbano por detrás y lo natural por delante y como tal es en este caso un fiel reflejo de las etapas de su rica historia. Es cierto que en gran medida mucha de su arquitectura del pasado se ha perdido en pos del progreso y la densificación urbana pero a la vez este conjunto heterogéneo puede leerse como la conformación de la identidad propia de una moderna ciudad costera.

La Bahía Bristol en el centro de la ciudad tiene su borde urbano dominado por la Rambla con los edificios gemelos del Hotel Provincial y el Casino diseñados por el Arquitecto Alejandro Bustillo. Este complejo de la década del cuarenta influenció con su estilo en gran medida a muchos otros que se construyeron a su imagen y semejanza a lo largo de su costa. Esa fachada homogénea se ve a su vez interrumpida por la presencia de la estructura más alta de Mar del Plata en la esquina de la calle Olavarría y la costa. El edificio Demetrio Elíades de 40 pisos proyectado en 1966 por el Arquitecto Juan Antonio Dompé es un fiel representante arquitectónico de su época y a la vez un ícono dentro del perfil urbano. Para contribuir a la gran diversidad de épocas, formas y estilos en la esquina opuesta a esta torre se encuentra un edificio que fuera la residencia de Concepción Unzué de Casares. Diseñada por el arquitecto francés Louis Faure Dujarric, el chalet pintoresquista de inspiración anglonormanda es uno de los pocos sobrevivientes de esas primeras décadas del Siglo XX, de esa Mar del Plata diseñada con estilo europeo para la clase alta porteña. Hoy en día subsiste como un emprendimiento gastronómico y gracias a que al igual que otras grandes residencias de principios del siglo pasado están alcanzada por la legislación local que protege al patrimonio arquitectónico de la ciudad.

Todo esto convive en escasos metros de frente urbano sobre el mar y así esta situación se repite a lo largo de su costa en los distintos sectores que la conforman. En Playa Chica y Playa Grande encontramos obras emblemáticas del movimiento moderno rioplatense como el Edificio Terraza Palace del arquitecto catalán Antonio Bonet junto otras grandes residencias como el ChaletSoulignacy la Villa Surula. Junto a estos destacados ejemplos surgen nuevas obras comolas Torres MaralEsplanada del arquitecto César Pelli actualmente en construcción que contribuye a esa percepción de ciudad contemporánea que no ha parado nunca de transformarse y adaptarse a los cambios sociales y las nuevas necesidades.

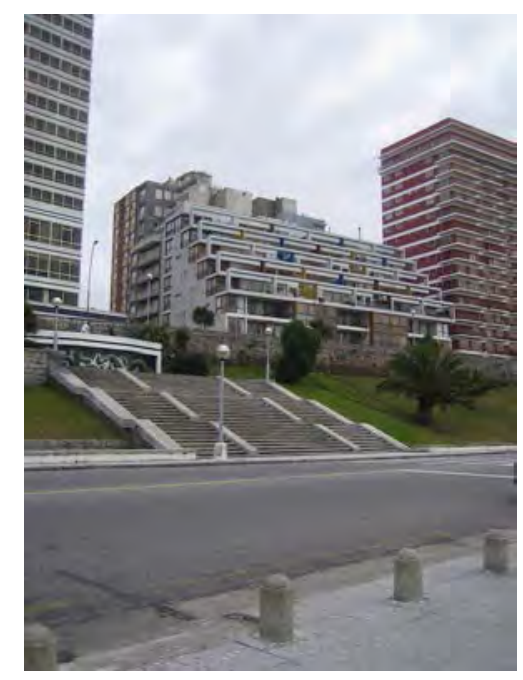

Figura 10: Edificio Terraza Palace, Playa Grande. 


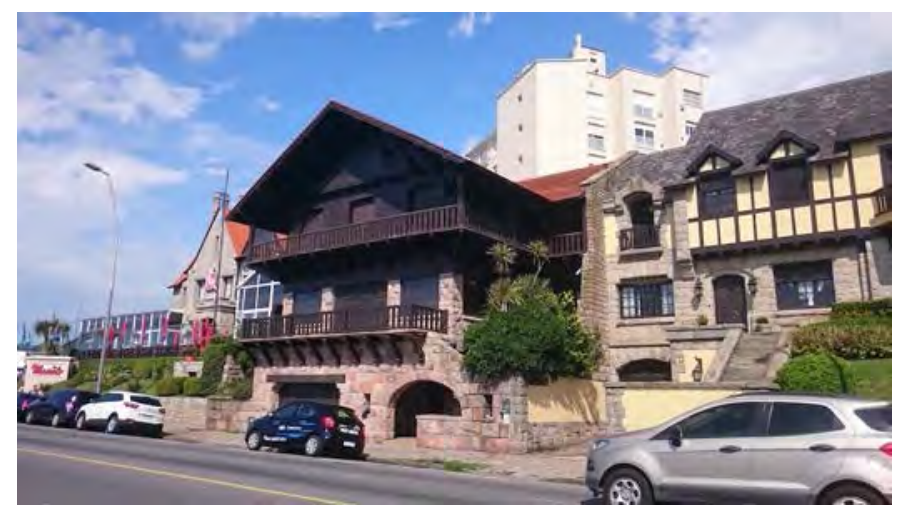

Figura 11: Villa Surula, Playa Chica.

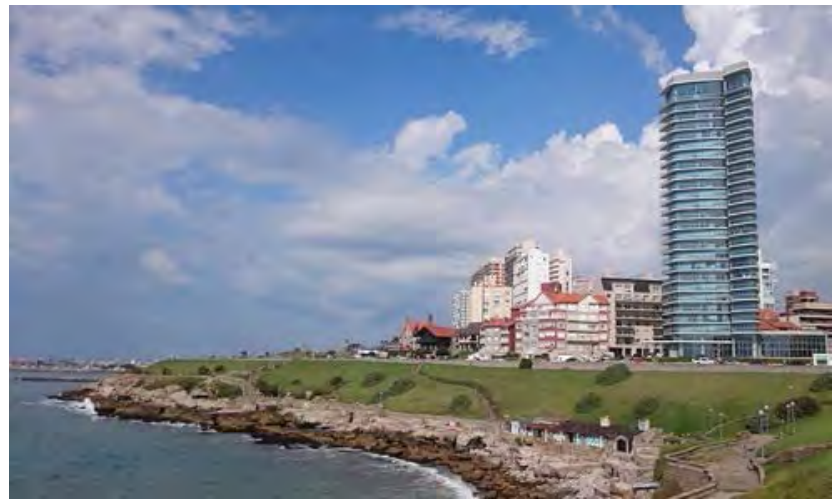

Figura 12: Torres Maral Explanada, Playa Chica.

\section{Conclusiones:}

La relación de Mar del Plata con su patrimonio natural y urbano arquitectónico es en gran medida controversial por los siguientes motivos:

Desde el punto de vista del patrimonio natural este ha sido preservado y conservado en gran medida a pesar de que en ese entorno se desarrolló una ciudad moderna y de escala considerable. Mar del Plata invirtió grandes recursos para salvaguardar el patrimonio principal de toda ciudad balnearia, la arena de sus playas, pero al mismo tiempo que esto se logró también es cierto que la solución trajo modificaciones no deseadas al ecosistema atlántico. Por otra parte, este fenómeno de construcciones de escolleras de piedra sobre el mar es único en la costa bonaerense.

El paisajismo aplicado a la barranca y a la costa es otro valor patrimonial de relevancia para la ciudad. Aquí es donde quizás las intervenciones a lo largo de los años fueron ideadas con mayor continuidad de criterio siempre privilegiando la idea de realzar la belleza natural del paisaje. También podemos decir que bajo ese ideal las soluciones que se realizaron difieren en cada sector de su costa por su forma y su momento histórico. Lejos de quitarle valor contribuyen con su diversidad a la riqueza del conjunto.

Por último, al abordar el patrimonio arquitectónico nos encontramos con que mucho de lo que fue su pasado glorioso ha desaparecido en manos del progreso urbano y la especulación inmobiliaria. En la última década se percibe la preocupante tendencia de utilizar bienes arquitectónicos patrimoniales para 
realizar emprendimientos inmobiliarios, preservando la obra original y agregando nuevos edificios de vivienda en sus lotes. Si bien esto da sostenibilidad económica a la preservación del bien, la alteración al entorno es tal que termina por modificar totalmente su valor.

Al mismo tiempo existen ejemplos de gran valor arquitectónico que además representan etapas fundamentales en el desarrollo de la ciudad.

Entonces cabe preguntarse si verdaderamente existe un patrimonio arquitectónico costero marplatense. Pensar en lo que se perdió no es el camino para encontrar la respuesta, pero si puede serlo considerar que el patrimonio es en definitiva aquello que refleja nuestra historia y nuestra identidad, que cuenta nuestro pasado y por lo que tuvimos que pasar para llegar al presente. Desde este punto de vista la costa marplatense representa un importante valor patrimonial y digno de ser preservado como legado para las futuras generaciones. Como aprendizaje del camino recorrido hasta ahora y como acción hacia el futuro nos queda pendiente como sociedad lograr ajustar las legislaciones vigentes en la materia para que las mismas protejan este patrimonio como conjunto y no como hechos aislados de su contexto.

\section{Referencias Bibliográficas}

COVA, R. O. (1992). Apuntes para una Historia de Mar del Plata. Mar del Plata: Universidad Nacional de Mar del Plata, Facultad de Arquitectura, Urbanismo y Diseño Industrial, Secretaría de Extensión Universitaria, 1992.

GÓMEZ CRESPO, R. A. (1982). Arquitectura Marplatense, el Pintoresquismo. Resistencia: Instituto Argentino de Investigación de Historia de la Arquitectura y del Urbanismo,

SÁENZ, J., Mar del Plata. Siglo I, 1874 - 1974. Buenos Aires: El Alba.

GASCÓN, J. C. (1942).Orígenes históricos de Mar del Plata. La Plata: Archivo Histórico.

GARCÍA, A. A (2011). Consecuencias del refulado para las playas y el puerto de Mar del Plata. La Capital de Mar del Plata, Mar del Plata: Editorial La Capital S.A. 20 de febrero de 2011.

FARRÉ, C. Mar del Plata perdió quince metros de costa en 15 años. Diario Perfil, Buenos Aires: Editorial Perfil S.A. 17 de enero de 2016.

Un no rotundo a las escolleras en “T”. La Capital de Mar del Plata, Mar del Plata: Editorial La Capital S.A. 6 de mayo de 2009.

Recibido: 4 de junio de 2019

Aceptado: 20 de septiembre de 2019 